SPONTANEOUS HYPOGLYCAEMIA WITH REPORT OF A CASE

BY

\author{
J. A. PRICE, M.D., M.R.C.P. \\ Assistant Physician, Royal Infirmary, Bradford
}

AND

\author{
A. B. RAPER, B.Sc., M.D., M.R.C.P. \\ Resident Medical Officer and Assistant Pathologist, \\ Royal Infirmary, Bradford
}

The syndrome of spontaneous hypoglycaemia is one that has received comparatively little attention in English medical literature, although numerous cases have been reported in America, Australia, and Europe; nor has it found a place in the standard textbooks of medicine in this country. Wauchope in her critical review (1933) quotes only one English case, that of Moore and his colleagues (1931), in which the syndrome resulted from amylaceous dyspepsia. Full descriptions of the clinical and pathological features of this condition have been given by several American authors, notably by Gammon and Tenery (1931) and Seale Harris (1933), who have also reviewed the literature; while in the last seven years eight cases have been reported in this country.

\section{Review of English Literature}

Ramsbottom and Eastwood (1932) recorded their experience with a woman aged 44 whose condition had been diagnosed by Dr. Eurich at the Bradford Royal Infirmary in 1930. This was a somewhat unusual case, in that Argyll Robertson pupils and extensor plantar responses were present in the intervals between attacks without any evidence of syphilis. At laparotomy no pancreatic abnormality was found, but an infected gall-bladder and appendix were removed, after which the patient improved temporarily, only to relapse in spite of a daily dose of 1 lb. of glucose. Barnard (1932) described a case in a woman aged 40 who died in hypoglycaemic coma, and in whom an adenoma of the islets of the pancreas was found; treatment with glucose had been tried with temporary relief, but glucose was ineffective in the final stages. Cairns and Tanner (1933) reported the case of a woman aged 52 who, after two years' history of recurrent "giddy" attacks, passed into hypoglycaemic coma. The blood sugar was found to be $41 \mathrm{mg}$. per $100 \mathrm{c.cm}$., and the patient died in spite of intravenous glucose injections, adrenaline, and pituitrin. Necropsy revealed an adenoma of the pancreas.

The case of a woman aged 41 who had previously received insulin treatment for diabetes was recorded by Griffiths and de Wesselow (1933). The sugar-tolerance curve of this patient was of the "lag" type with a final hypoglycaemia, and the clinical course and laboratory findings were noticeably erratic-features which we:? observed in some of Wilder's (1927) cases, and considered by Howland (1929) to suggest a malignant rather than a benign growth. There was no clear evidence of liver dysfunction, though on one occasion the adrenaline test gave negative results. Moore et al. (1934) recorded a case which they considered to be due to subacute parenchymatous hepatitis; they also gave the ultimate history of a previously reported case (1931), and mentioned having seen another case, in a man of 28 , of "apparently true hyperinsulinism." One of the patients referred to by Jones (1935) as presenting mental symptoms due to hypo-glycaemia was a man of 31 , and the details given leave little doubt that he suffered from spontaneous hypoglycaemia of pancreatic origin.

We present below the records of another example of spontaneous hypoglycaemia. It is probable that the condition is not so rare as is generally supposed, and that as its features are more widely known it may be increasingly recognized, and experience with a larger number of cases may enable a truer assessment to be made of the possibilities of treatment.

\section{Case Report}

A man aged 41, a painter, was referred to one of us as a " peculiar epileptic." For the past eleven years he had suffered from attacks of dizziness and unsteadiness of gait. At first these occurred only once or twice a year, but they had increased in frequency latterly, so that in the past year he had had one or two a week, and in the week before his admission to the Bradford Royal Infirmary on February 27, 1938, they were of daily occurrence ; his doctor described him as "a nuisance to the neighbourhood" by reason of his malady. The patient had previously been healthy except for an attack of influenza in 1918; he had begun to put on weight at about the age of 30 , when symptoms first appeared, but his weight had remained stationary at about 13 stone for the last few years. His parents, four sisters, and one brother are alive and well, and do not suffer from any symptoms that might be ascribed to hypoglycaemia or diabetes.

\section{NATURE OF THE ATTACKS}

Attacks are almost always heralded by a sensation of tingling, which is felt first in the lips when he is eating, in the right hand when he is engaged in manual work, and in the feet when he is walking. If an attack begins while he is reading the newspaper the first sign would be that the words "run together." After these prodromal symptoms the commonest form taken by the attack is a sensation described as "muzziness of the head" accompanied by lack of concentration, slight blurring of vision, and some confusion. Occasionally hallucinations occur, and as a result of these "dreams" the patient exhibits unusual though never violent conduct. During an attack his speech is slow and drawling and the attention wanders; there has never been any sphincter disturbance, abnormal sleep, headache, convulsion, or loss of consciousness. On two occasions, the first many years ago and the second fourteen months ago, the patient found that the right arm and leg became useless during an attack; the face has never been affected. The paresis lasted a few hours on each occasion and disappeared gradually.

More severe attacks have occurred, usually when walking home from work; tingling in the feet is followed by a drunken feeling and unsteadiness of gait, so that he leans for support on a wall or railing. The attack develops slowly enough for him to board a bus and reach his home; but here he collapses in a chair, feeling cold, faint, and confused, and often sweating. An attack may last for half an hour to one and a half hours, and always develops and passes off slowly. Most frequently attacks occur towards the end of the day's work, but they have also occurred before mealtimes and sometimes during a meal. The patient does not experience hunger during an attack, but he knows that if he takes food he can prevent a severe one developing, and he has formed the habit of having a mid-morning lunch at work for this reason.

\section{EXAMINATION}

The patient was a moderately obese subject weighing 13 stone with an old-standing strabismus and myopia. The fat was of normal distribution, there was no unusual pigmentation of the skin, the hair was normal, as was the development of the sexual organs. Examination of the nervous system revealed no abnormal signs, while the only abnormality found in a general examination was a blood pressure of $170 / 100$ $\mathrm{mm}$. $\mathrm{Hg}$. The urine and the cerebrospinal fluid were normal, and the Wassermann reaction was negative. 
From a description of the attacks hypoglycaemia was suspected, and this view was confirmed on reducing the diet the next day. Whilst having his tea on this day the patient developed a typical attack in which the blood sugar was found to be $40 \mathrm{mg}$. per $100 \mathrm{c.cm}$. The sugar-tolerance curve after 50 grammes of glucose gave the following results:

\begin{tabular}{|c|c|c|c|c|c|}
\hline Time $\quad \ldots \quad \ldots$ & Before Sugar & 30 mins. & 60 mins. & 90 mins. & 120 mins. \\
\hline $\begin{array}{l}\text { Blood sugar (mg. per } 100 \\
\text { c.cm.) }\end{array}$ & 25 & 40 & 92 & 75 & 66 \\
\hline
\end{tabular}

There was no glycosuria during the test, but sugar was found on one occasion in the early morning urine.

Further investigations to determine the aetiology of the hypoglycaemia were undertaken; the stools contained no undigested starch, and no diarrhoea was present. Pituitary function appeared to be normal, there was no radiological abnormality of the pituitary fossa. and the fields of vision were normal. The basal metabolic rate gave a value of -3 per cent. A test meal showed a rapid emptying time and a normal acid curve. There was no evidence of diminished laevulose tolerance. After a dose of 40 grammes of laevulose the following figures were obtained:

\begin{tabular}{lr|c|c|c|c|c}
\hline Time &.. & Before Laevulose & 30 mins. & 60 mins. & 90 mins. & 120 mins. \\
$\begin{array}{l}\text { Blood sugar (mg. per } \\
100 \mathrm{c.cm} \text { ) }\end{array}$ & 31 & 31 & 28 & 24 & 20 \\
\hline
\end{tabular}

Mobilization of sugar occurred normally after the subcutaneous injection of 10 minims of adrenaline :

\begin{tabular}{l|c|c|c|c|c|c|c}
\hline Time $. . \quad .$. & $\begin{array}{c}\text { Before } \\
\text { Adrenaline } \\
66\end{array}$ & 10 mins. & 20 mins & 30 mins. & 40 mins. & 50 mins. & 60 mins. \\
$\begin{array}{r}\text { Blood sugar (mg. } \\
\text { per } 100 \text { c.cm.) }\end{array}$ & 96 & 130 & 145 & 146 & 186 \\
\hline
\end{tabular}

\section{Discussion}

Various authors have discussed the pathogenesis of hypoglycaemia, and its possible causes have been summarized by Wauchope (1933) as follows:

1. Excess of Insulin.-Therapeutic injections. Tumours and hyperplasia of the pancreas. Functional hyperinsulinism (idiopathic hypoglycaemia).

2. Lack of Opposing Secretions.-Disease of the suprarenal glands. Pituitary tumours: posterior lobe, anterior lobe (acromegaly). Myxoedema.

3. Lack of Glycogen.-Destruction of reservoirs: disease of the liver; wasting of muscles. Abnormal excretion of sugar: renal diabetes; lactation. Active depletion of stores: muscular exercise. Failure to replenish stores: starvation.

4. Interference with Regulating Centre.-Nervous disease affecting the pons. Overaction of the vagus.

In the present case no evidence had been obtained of disorder of the adrenal, pituitary, or thyroid glands ; liver and gastro-intestinal functions were normal, and there was no renal diabetes. It seemed, therefore, that the cause must be sought in the pancreas.

From a study of the previously reported cases it appears that there is as yet no satisfactory criterion whereby the varieties of pancreatic hypoglycaemia may be differentiated. In the cases reported up to 1931 (Gammon and Tenery, 1931) the average duration of symptoms when a patient was first seen was two and a half years in the tumour group and four years in the non-tumour group, the longest periods being seven years and thirteen years respectively in the two groups. The erratic course of tumour cases has been stressed, but this has not been apparent in all such cases, although it might seem feasible that an adenoma or carcinoma, presumably exempt from nervous control, should show a fluctuation in its functional activity dependent upon variations in its rate of growth. From those cases in which the adrenaline response has been observed there is some reason to suppose that it is more often negative in tumour cases, but the difficulties in interpreting this test are pointed out by Cammidge and Poulton (1933). The latter incline to the view that lack of response to adrenaline cannot be due to pancreatic hyperfunction, and criticize Wilder's explanation that the adrenaline must be swamped by excess of insulin, on the grounds that a balance must always exist, and that this must always be susceptible to alteration on the addition of more adrenaline. If, however, Wilder's view is correct, a negative adrenaline response might indicate exhaustion of the adrenaline-supplying mechanism, or possibly a diminution in sensitivity to adrenaline. In either case it would be expected to denote the severity of the disease rather than its pathological basis, and this is borne out by the fact that adrenaline often fails to relieve severe hypoglycaemia from any cause. The state of affairs in the pancreas is not always capable of diagnosis even at laparotomy, for small adenomata may be missed (Ziskind and Bayley, 1937).

On the evidence available, therefore, we concluded that a definite pathological diagnosis could not be made, and that there was as yet no indication for exploratory laparotomy.

\section{Treatment}

Medical treatment is of course palliative. Its aim is to keep the blood sugar from falling too low, and also from fluctuating too violently. To assess the value of the different methods available we first observed the bloodsugar variations in the patient on an ordinary ward dietary, and the results are shown in Fig. 1.

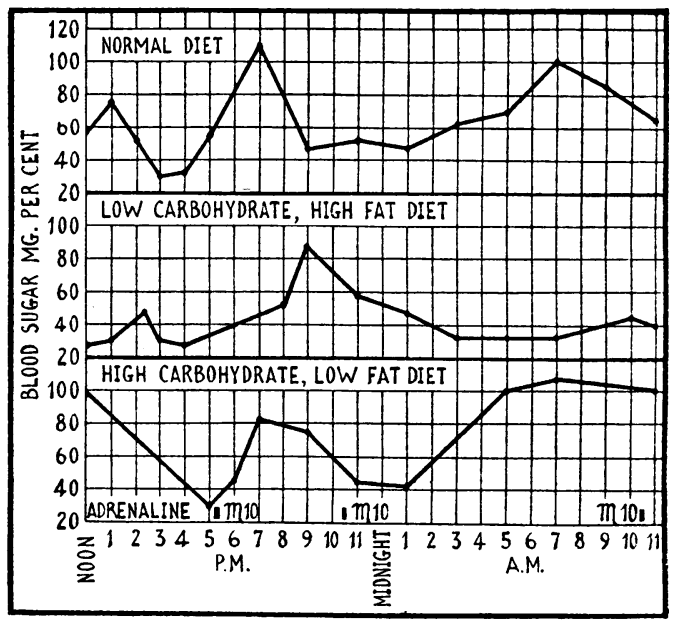

FIG. 1 .

It has been suggested (Harris, 1933) that rational therapy should consist in measures which avoid stimulation of pancreatic activity. Accordingly the patient was given a diet consisting of carbohydrates 100 grammes, protein 70 grammes, and fat 160 grammes, and on the third day of this regimen the blood-sugar variations were again followed (Fig. 1). On the first day of this diet the patient felt worse than at any time since admission, but he had improved considerably by the fifth day. On the sixth day, however, he had a severe attack in which there was twitching of both legs but no other abnormal nervous signs. During all this period he complained of being "terribly tired." A diet of carbohydrates 500 grammes, 
protein 70 grammes, and fat 70 grammes was then given, divided into seven meals. Subjectively his condition on this diet was better than with the previous one, though he still had "pins-and-needles" in the lips. The diet was then supplemented by injections of 10 minims of adrenaline at 5.30 p.m., 10.30 p.m., and 10.30 a.m., and the results of this appear in Fig. 1. A week later he had had no tingling of the lips for a few days, and stated that he would be quite satisfied if his present condition remained unchanged. He was discharged on the high carbohydrate diet, and ephedrine, $\frac{1}{2}$ grain thrice daily by mouth, was substituted for the injections of adrenaline.

On July 7, 1938, the patient was readmitted. Subsequent to his discharge he had had no attacks for six weeks, but had had a total of four attacks in the whole period of fifteen weeks. His weight had been stationary, and his general health and temper had improved; the blood pressure remained at $170 / 100 \mathrm{~mm}$. $\mathrm{Hg}$. The patient stated that on each occasion an attack had been the result of a delayed meal, and that with greater care he could have prevented them. The ephedrine was stopped temporarily and the daily blood-sugar variations again recorded while the patient was taking the 500gramme carbohydrate diet. The results given below indicate that a higher blood-sugar level had now been attained, and it was also noted that prodromal symptoms of hypoglycaemia occurred at a higher level of blood sugar than previously, suggesting that during the previous weeks the nervous system had become accustomed to more normal conditions.

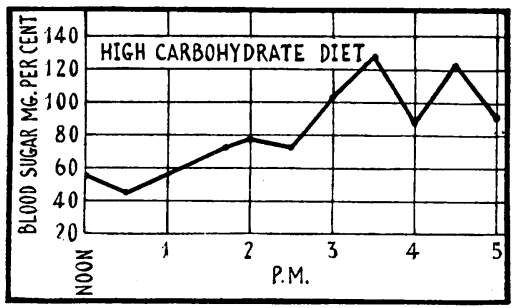

FIG. 2.

The duration of the response to ephedrine was next determined, and as it was found to cause a rise of blood sugar, beginning about three hours after administration and lasting two hours, the patient was discharged on July 15, 1938, with instructions to take ephedrine tablets four times daily at approximately 8 a.m., noon, 5 p.m., and bedtime. His diet was rearranged to contain 650 grammes of carbohydrate, divided into ten meals.

In view of the good response to medical treatment exploratory laparotomy was further postponed.

\section{Commentary}

One of the most striking features of this case is the extraordinarily low blood-sugar readings obtained in the absence of severe hypoglycaemic symptoms. Figures in the region of $30 \mathrm{mg}$. per $100 \mathrm{c.cm}$. were recorded several times, and even when the blood sugar reached the level of $16 \mathrm{mg}$. on one occasion and $20 \mathrm{mg}$. on another the patient was not in coma. So far as we are aware this has not been recorded before. (The blood sugar was estimated by a modification of the method of Calvert (1924) using the Zeiss photometer, and the technique was checked by estimation of glucose solutions of known strength.)

It will be noted that the point at which tingling or weakness first appeared was often determined by use of the part-for example, tingling of the legs when walking and of the lips when eating-suggesting that some local product of muscular metabolism was the determining factor. Generalized muscular weakness of sudden onset in familial periodic paralysis is known to be associated with a fall in blood potassium, and an attack in this condition may be brought on by administration of glucose or insulin, or both together (Aitken and Allott et al., 1937). In chronic hypoglycaemia the same biochemical abnormalities may occur, and it is possible that in the case here recorded the extra demand of neuromuscular activity interfered with the already disturbed potassium balance and produced the symptoms noted. The fall in the blood potassium was confirmed in the present case, for during a hypoglycaemic attack in which the blood sugar was $30 \mathrm{mg}$. per $100 \mathrm{c.cm}$. and weakness of hand-grip was evident the serum potassium fell from its normal of $21.4 \mathrm{mg}$. to $15.9 \mathrm{mg}$. per $100 \mathrm{c.cm}$. Unfortunately the effects of administration of potassium salts have not been observed.

Another unusual point concerns the time of onset of symptoms. Most cases show symptoms when fasting, and especially just before meals, but here it was repeatedly observed that the attacks began just after the patient had started to eat. This might be merely another example of the local effects of exercise mentioned above, the blood sugar being already low, or it might be due to an actual lowering of the blood sugar, presumably by means of a conditioned reflex. The same effect was noted by Howland (1929). Personal experiments on a normal subject, however, lent no support to the hypothesis that a reflex lowering of the blood sugar occurred when a meal was contemplated. Moreover, Howland's case was one of carcinoma, which could not be expected to be susceptibie to nervous impulses.

Lastly, it may be pointed out that hemiparesis is a recognized though uncommon feature of hypoglycaemia, and it is important to recall the fact that this rather alarming occurrence may be a transient manifestation of the condition. We have come across similar attacks in a diabetic boy aged 11 years who was receiving protamine insulin, and in an adult aged 30 under similar conditions.

\section{Summary}

1. References to spontaneous hypoglycaemia in the English literature are reviewed.

2. The records of an additional case are presented and the difficulties of diagnosis and treatment discussed.

3. Certain unusual features in the symptomatology are commented uppn.

\section{REFERENCES}

Aitken, R. S., Allott, E. N., et al. (1937). Clin. Sci., 3, 47. Barnard, W. G. (1932). J. Path. Bact.. 35, 929.

Cairns, R. M., and Tanner, S. E. (1933). British Medical Journal, 1,8 .

Calvert, E. G. B. (1924). Biochem. J., 18, 839.

Cammidge, P. J., and Poulton, E. P. (1933). Lancet, 1, 520.

Gammon, G. D., and Tenery, W. C. (1931). Arch. intern. Med., 47, 829.

Griffiths, W. J., and de Wesselow, O. L. V. (1933). Lancet, 1, 519.

Harris, S. (1933). J. Amer. med. Ass., 101, 1958.

Howland, G., et al. (1929). Ibid., 93, 674.

Jones, M. S. (1935). British Medical Journal, 2, 945.

Moore, H., O'Farrell, W. R., Malley, L. K., and Moriarty, M.A. (1931). Ibid., 2, 837 .

- and Headon, M. F. (1934). Ibid., 1, 225.

Ramsbottom, A., and Eastwood, C. G. (1932). Ibid., 1, 833.

Wauchope, G. M. (1933). Quart. J. Med., n.s. 2, 117.

Wilder, R. M., et al. (1927). J. Amer. med. Ass., 89, 348.

Ziskind, E., and Bayley, W. A. (1937). J. Lab. clin. Med., 23, 231. 